\title{
A Bottom-Up Model to Evaluate the Flexibility of French Residential Wet Appliances
}

\author{
Jérôme Le Dréau ${ }^{1}$, Marika Vellei $^{1}$, Yassine Abdelouadoud ${ }^{2}$ \\ ${ }^{1}$ La Rochelle University, La Rochelle, France \\ ${ }^{2}$ CSTB, Sophia Antipolis, France
}

\begin{abstract}
The manual shift of residential wet appliances (dishwashers, washing machines and tumble dryers) in French households that have subscribed to a Time of Use (ToU) tariff represents a flexibility potential available already today and at zero-cost. To quantify this flexibility, a bottom-up model is here proposed and validated. This includes a stochastic occupant behaviour model for predicting the use of the wet appliances and an overlying agent-based model to predict their shifting under the ToU tariff. The model is validated using empirical data collected in a recent monitoring campaign, which provided energy measurements from 60 dishwashers, 100 washing machines and 23 tumble dryers in 107 French households for a period of 1 year.
\end{abstract}

\section{Introduction}

Demand response (DR) is an inexpensive and efficient solution to deliver flexibility to the future electricity system. In France, it is estimated that DR in the residential sector will contribute, both via direct and indirect control mechanisms, to $1 \mathrm{GW}$ of additional flexibility by 2030 ; lower than the additional $3 \mathrm{GW}$ expected from the industrial sector, but comparable to $1 / 2 \mathrm{GW}$ expected from batteries and $1 / 2 \mathrm{GW}$ from pumped hydro energy storage (RTE, 2017b).

For residential customers, different price-based schemes can be adopted to incentivize DR. Examples are ToU tariffs, Critical Peak Pricing (CPP), Critical Peak Rebate (CPR) and/or Real Time Pricing (RTP). In France, households have the option to choose a ToU tariff: in 2018 14.6 million French households (about $41 \%$ of all the French households) have chosen to adopt a two-rate ToU tariff system instead of a more conventional single-rate flat tariff (Enedis, 2019).

The French two-rate ToU tariff has historically been used to shift the use of domestic hot water heaters during the night or in the middle of the day in correspondence with the off-peak hours, when the cost of electricity is low because of the low electricity demand. Monitored electricity data (ADEME, ENERTECH, and EDF, 2008; ENERTECH, 2016) shows that French households have further exploited their flexibility by also shifting their wet appliances. Wet appliances represent an important share (about 13\%) of the electricity consumption in French households (RTE, 2017a). A share which is expected to increase in the future due to the reduction of space heating needs and the replacement of conventional electric resistance water heaters with more efficient heat pump water heaters.

While domestic hot water heaters can be automatically set to heat the water during the off-peak hours, today's smartest wet appliances imply the users to be manually engaged with the shifting. Built-in delay functionalities, which are now becoming increasingly available, allow the users to either shift the starting time by a defined number of hours or to end the process at a predefined time. Consumer survey data collected in Europe (Stamminger and Schmitz, 2017) shows that France is the European country with the highest percentage of washing machines having a delay functionality built-in (in over $70 \%$ of the surveyed households) and with its highest usage for shifting the load towards the off-peak periods of the day (55\%). For the dishwashers the situation is similar: France is the country where the delay function is most often used for load shifting (by almost $80 \%$ of the households) and where most of the surveyed households have such a function available in their dishwashers (in almost $70 \%$ of the surveyed households). This is happening despite the very low cost savings achievable when households use a ToU tariff (Gottwalt et al., 2011).

Users' flexibility towards the use of wet appliance is most often studied using top-down models, such as demandprice elasticity matrices (Venkatesan, Solanki, and Solanki, 2012). It is more difficult to create bottom-up models since they require a detailed modelling of the stochastic behaviour of the occupants. Example of flexibility bottom-up models are given by the works of: (Fischer et al., 2017; Gottwalt et al., 2011; McKenna and Keane, 2016; Sancho-Tomás et al., 2017). Gottwalt arbitrarily defines different smart mode scenarios for each wet appliance (e.g., 3 scenarios are defined for the washing machine, in scenario 1 it has to finish within $5 \mathrm{~h}$, in scenario 2 within $10 \mathrm{~h}$ and in scenario 3 before the next day at 6am) and randomly selects one scenario each time a wet appliance is used (Gottwalt et al., 2011). In the work of Fischer, the start of each appliance is shifted based on a user response rate which is appliance-specific and is derived from 350 questionnaires collected during a pilot experiment (Fischer et al., 2017). However, occupants' self-reported flexibility might not actually coincide with their actual flexibility. In addition, the response rate is assumed constant during the day. McKenna relates a change in the probability of a switch-on event to a change in price, by using both self-elasticity and cross-elasticity coefficients, which are derived from previous studies of demand-price elasticity matrices (McKenna and Keane, 
2016). In the work of Sancho-Tomás, device-agents use Q-learning algorithms to maximize a cost reward function (Sancho-Tomás et al., 2017).

These models neither are based on empirical data nor are validated against data collected in real households. In this paper, a new bottom-up model able to predict the flexibility of French wet appliances is introduced and validated using monitored data from French households. This new model includes a stochastic occupant behaviour model for predicting the use of the wet appliances and an overlying agent-based model to predict their shifting under ToU tariffs.

\section{Methods}

\section{Simulation platform}

The bottom-up stochastic occupant behaviour model for predicting the use of the wet appliances is embedded within the simulation platform DIMOSIM (DIstrict MOdeller and SIMulator), which can be used to model energy demand at district level (Riederer et al., 2015).

In the first part of the paper, the model of wet appliance usage (as implemented in DIMOSIM) is presented and validated, focusing especially on the following aspects:

- the suitability of using Time Use Survey (TUS) data to represent the activities related to the wet appliances,

- the validity of the unit load curves,

- the validity of the simulation procedure.

In the second part of the paper, the model of wet appliance flexibility is described and validated. The modularity of the code (written in Python 2.7) allows for the development of a new independent component, which could be directly integrated in DIMOSIM. The simulation principle is presented in Figure 1.

\section{Validation Procedure}

The two models are validated using data collected in a monitoring campaign performed in 2015 and providing energy measurements from 60 dishwashers, 100 washing machines and 23 tumble dryers in 107 French households at an interval of ten minutes for a period of 1 year (Dupret and Zimmermann, 2017; ENERTECH, 2016).

The household sample was selected to be as representative as possible of the French residential sector by taking into consideration the following criteria:

- geographic location,
- type of residence (single-family home or flat),

- household location (city or countryside),

- household composition,

- household socio-economic characteristics.

The selected sample is representative of the national characteristics except for one criterion, the socioeconomic characteristics of the households. In fact, managers and professionals are overrepresented in the sample (34\% instead of $11 \%$ at the national level). Around $41 \%$ of the monitored households has subscribed to a two-rate ToU tariff system. This rate is the same as the national value (Enedis, 2019).

The sample is generated in the DIMOSIM platform in a deterministic way by first defining the number of occupants and their occupation (employed, unemployed, retired, student...) for each household. Children are assumed to be students as they follow a similar daily pattern. The wet appliances are then assigned to the different households. Despite a thorough description of the sample, some information is missing to define all the parameters in a deterministic way. For example, it is known that there are 60 dishwashers but it is unknown which particular household of the 107 monitored households has a dishwasher. There is also no information on the relationship between the energy class of the equipment and the size of the household (or the occupation of the occupants). Hence, the wet appliances and their features (energy class and capacity) are randomly allocated to the households based on the available distributions of the energy classes and capacities. This implies that the generation of the sample is partly performed in a stochastic way. Several simulations (around 100) are then necessary for the convergence of the results in terms of mean values and standard deviations. The simulation time-step is set to 10 minutes to capture the dynamics of the district when observing hourly patterns.

For each studied appliance, different metrics are evaluated to assess the validity of the model:

- The annual number of cycles and the annual energy consumption (per household and per person). Both mean values and standard deviations are compared.

- The distribution of the energy consumption (ratio weekends/weekdays, ratio off-peak/peak hours, hourly patterns).

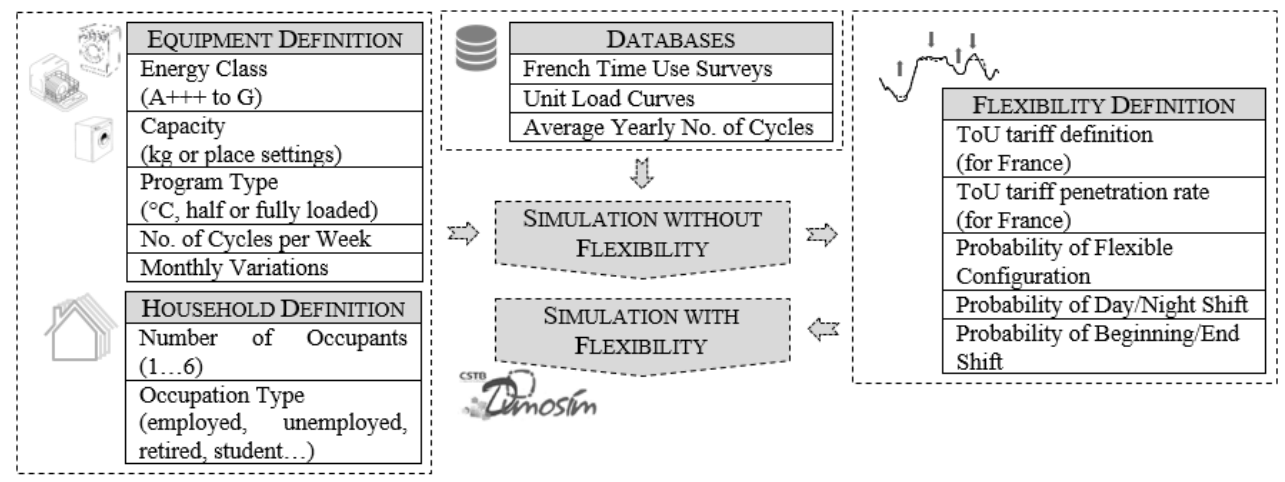

Figure 1: Simulation framework. 


\section{Model of wet appliances usage}

To develop stochastic appliance use models, TUS datasets are generally preferred over monitored data obtained using electrical power sensors since they are bigger in size (reporting daily activities of thousands of occupants) and better capable of reproducing the behavioural diversity of the real population (Yan et al., 2015). Thus, the model of wet appliances usage is based on TUS data collected in France from September 2009 to September 2010 (INSEE, 2010c). The French 2009-2010 TUS study involved 12000 responding households. A randomly chosen household member (aged 11 or more) was given a daily logbook, where he/she could note its activity (by choosing among 140 activities) each 10 minutes for two days (one weekday and one weekend day). If this member had a spouse, he/she was also included in the sample. Other characteristics were also collected, including the date of the survey, the household composition and the respondent's employment/education status.

\section{Step 1: identifying clusters of habits}

About 27900 daily logbooks are available for building the model. These 27900 daily times series are first grouped according to the type of occupant (employed, unemployed, retired, student...) and the day of the week (weekends and weekdays). Within each group, a hierarchical agglomerative clustering (HAC) using the Jaccard distance metric and the Ward's linkage criterion is performed to find clusters of similar daily profiles. This is based on the assumption that most human behaviour is habitual and thus repeats itself over the year. The elbow method is used to find the appropriate number of clusters for each group, which is reported in Table 1.

The following procedure is then applied to create different yearly time series:

- Draw both a weekend and a weekday cluster in the list of clusters corresponding to the type of occupant being simulated.

- Draw the weeks of vacation according to INSEE data (INSEE, 2010b).

- For each day of the simulation:

- If it is a weekday, draw a daily schedule in the weekday cluster and apply it.

- If it is a weekend, draw a daily schedule in the weekend cluster and apply it.

- If it is a vacation day, set the activity to other outside.

If a household includes more than one occupant, the yearly time series of each occupant are summed up together. The main limitations of this approach are:

- the possible incoherence between occupants of the same household as their schedules are drawn independently,

- the lack of seasonality,

- the possible bias due to self-reporting (for example, television use is largely under-reported compared to other studies).

For the dishwasher, an activity dishwashing is directly available in the French TUS dataset. For the washing machine, the activity laundry is selected. While, for the tumble dryer there is not a corresponding activity, the use of the tumble dryer is thus assumed to follow the laundry activity. These different activities can be considered as flexibility-free since the appliance built-in delay functionalities allow for a decoupling of the activities from the starting times of the appliances.

Table 1: Number of daily logbooks and clusters within each group.

\begin{tabular}{|c|c|c|c|}
\hline $\begin{array}{c}\text { Type of } \\
\text { Occupant }\end{array}$ & $\begin{array}{c}\text { Type of } \\
\text { Day }\end{array}$ & $\begin{array}{c}\text { No. of } \\
\text { logbooks }\end{array}$ & $\begin{array}{c}\text { No. of } \\
\text { Clusters }\end{array}$ \\
\hline \multirow{2}{*}{ Employed } & Weekday & 7729 & 15 \\
& Weekend & 6200 & 20 \\
\hline \multirow{2}{*}{ Student } & Weekday & 763 & 9 \\
& Weekend & 760 & 8 \\
\hline \multirow{2}{*}{ Unemployed } & Weekday & 887 & 11 \\
& Weekend & 748 & 6 \\
\hline \multirow{2}{*}{ Retired } & Weekday & 4357 & 15 \\
& Weekend & 4221 & 10 \\
\hline \multirow{2}{*}{ Stay-At- } & Weekday & 817 & 7 \\
Home & Weekend & 709 & 4 \\
\hline \multirow{2}{*}{ Other } & Weekday & 323 & 4 \\
& Wee & 318 & 2 \\
\hline
\end{tabular}

\section{Step 2: drawing the right number of events}

The created yearly time series for each appliance can contain more events than the actual switch-on events, since, for example, washing the dishes by hand or loading/unloading the dishwasher are activities that take more than 10 minutes. Hence, a defined number of events is drawn from the yearly time series of the TUS-activity starts based on the ratio:

$$
\frac{n_{\text {cycles }}}{n_{\text {TUS starts }} * n_{\text {occupants }}}
$$

Where $n_{\text {cycles }}, n_{\text {TUS starts }}$ and $n_{\text {occupants }}$ are the average number of cycles per week, TUS starts per week and occupants per household, respectively. Thus, it is assumed that a cycle always corresponds to the same number of TUS-activity starts, independently of the number of TUS-activity starts of the simulated household (i.e. linear relationship). $n_{\text {occupants }}$ is set equal to 2.3 based on the average French national value (INSEE, 2010a). $n_{\text {cycles }}$ is based on the available monitored data (ENERTECH, 2016):

- Dishwasher: 3.5 cycles/week.

- Washing Machine: 3.2 cycles/week.

- Tumble Dryer: 2.7 cycles/week.

These values, which are very close to the average French national values (Stamminger and Schmitz, 2017), could also be set based on average values for Europe (AISE, 2017).

Furthermore, a monthly variation of the drawing probability is added to the model of the tumble dryer to account for the possibility to dry the clothes outside during the summer period (ENERTECH, 2016). 


\section{Step 3: adjusting the starting times}

For the tumble dryers, a shift (based on an exponential distribution having lambda equal to 2) of the selected washing machine events is added to account for the waiting time between the washing and drying activities. The lambda value is estimated based on empirical observations. A future development of the model should include a more rigorous way to estimate this parameter.

Finally, events that are too close to each other are removed from the list and are substituted with new randomly drawn events. The minimum time between two events is equal to the maximum length of a cycle.

\section{Step 4: adding the unit load curves}

The unit load curves of the different types of program are randomly assigned to the starting times. The share of the different program types is either based on the monitored data (ENERTECH, 2016) or on general survey data for Europe (AISE, 2017). 1200 unit load curves are defined to account for the diversity of equipment that can be encountered in a population. The energy rating ranges from $\mathrm{A}+++$ to $\mathrm{G}$ for all three devices. The different capacities and types of program are the following:

- Dishwasher: capacity (4 to 21 plates), type of program (standard, eco, fast, auto).

- Washing machine: capacity (5 to $10 \mathrm{~kg}$ ), temperature of the program (cold, $30,40,60,90^{\circ} \mathrm{C}$ at full charge and 30 and $40^{\circ} \mathrm{C}$ at half charge).

- Tumble dryer: capacity (4 to $6 \mathrm{~kg}$ ), full/half charge.

The unit load curves are built based on the EU labelling scheme for electronic devices (EU, 2010).

\section{Results of the validation}

The uncertainty of the simulation results is evaluated by performing a set of 100 simulations of the sample (constituted of 107 households). The unknown characteristics generate uncertainty, which can be observed in the boxplots of Figure 2, Figure 3, Figure 4 and Figure 5. In these figures, half of the data is distributed within the box and the data outside the whiskers represents outliers.

The uncertainty on the measured results also needs to be taken into account since the size of the sample is relatively limited (from 100 washing machines down to 23 tumble dryers). The uncertainty on the mean values of the measurements is evaluated using the Student's $t$ distribution ( $n$ being the size of the sample):

$$
\bar{x} \pm \frac{t_{n-1\{95 \%\}}}{\sqrt{n}} \sigma
$$

A large uncertainty on the measured mean values is evident for the small sample of the tumble dryers.

The comparison of the simulated and measured average number of annual cycles is presented in Figure 2. The coherence between simulated and measured mean values confirms the validity of the simulation procedure. As the average annual number of cycles per household is correctly simulated, the average annual energy consumption can be compared. From Figure 3, a good agreement between simulated and real sample can be observed (the mean values are within the uncertainty bands), except for the annual consumption of the washing machine, which is slightly overestimated. The average energy use per cycle for this equipment is higher than the one measured, which can be explained by the lack of information on the energy class (almost half of the devices' energy class is unknown for the washing machine). To be conservative, it has been assumed that the distribution of the energy classes of the equipment without energy labelling follows the distribution of the available energy classes. However, these devices might have a better energy class as the household sample is skewed towards high socio-economic categories. Furthermore, high socio-economic categories might have more energy-efficient laundry habits (e.g. low temperature washing).

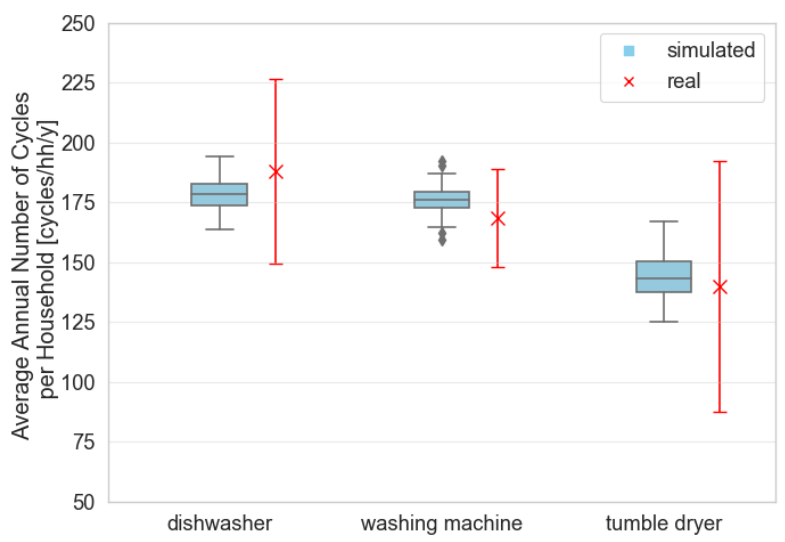

Figure 2: Average annual number of cycles per household (mean value over 107 households). Each boxplot represents 100 data points from 100 simulations.

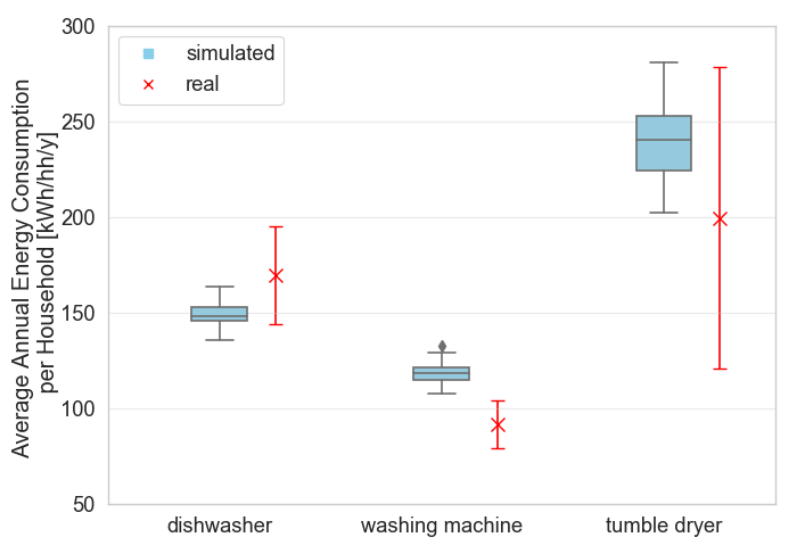

Figure 3: Average annual energy consumption per household (mean value over 107 households). Each boxplot represents 100 data points from 100 simulations.

To ensure a correct repartition of the white goods usage across the sample, the distribution over the different sizes of household has been evaluated in terms of cycles/person/year for the dishwashers (Figure 4) and the washing machines (Figure 5). It can be observed that the simulated and real samples have similar trend: the average values per person are higher for households of 1 and 2 persons and then decrease for larger households. 


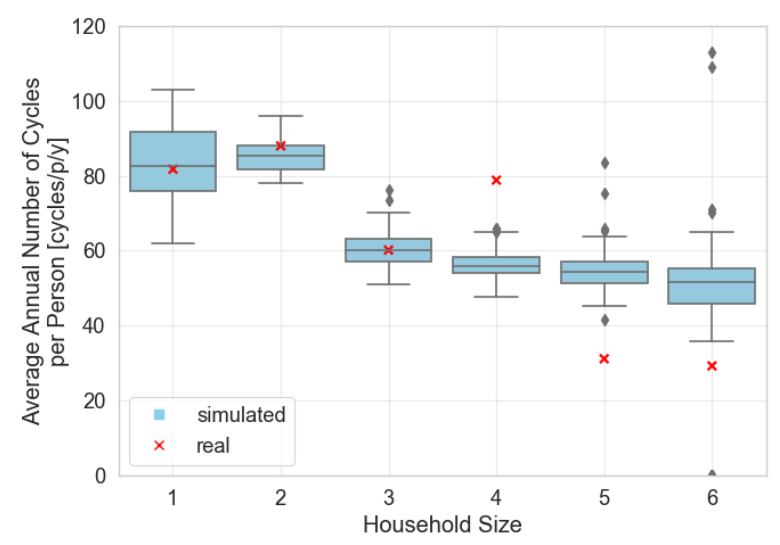

Figure 4: Average annual number of cycles per person for the dishwashers over households of different size.

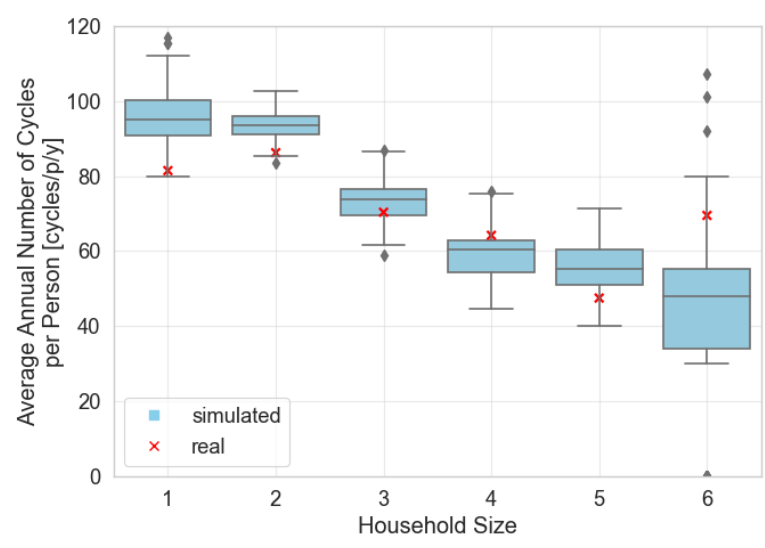

Figure 5: Average annual number of cycles per person for the washing machines over households of different size.

Evaluating the average values over the 107 households is not sufficient to validate the model. The diversity within these 107 households needs to be assessed too. Therefore, the standard deviation of the usage frequency and energy consumption has been compared for the real and simulated sample (Table 2). The simulation platform is not able to reproduce the diversity that has been observed in the sample. The simulated standard deviations are less than the real values. It should be noted that the monitored diversity is extreme: for example, the number of cycles per year for the washing machine ranges from 443 down to 8 cycles/year. Our used method produces average profiles and does not include special events that could increase or decrease the number of normal cycles, such as out-of-service periods of the machines, long periods away from home or long sicknesses at home.

Table 2: Standard deviation within the simulated and real population.

\begin{tabular}{|c|c|c|c|c|}
\cline { 3 - 5 } \multicolumn{2}{c|}{} & $\begin{array}{c}\text { Dish- } \\
\text { washer }\end{array}$ & $\begin{array}{c}\text { Washing } \\
\text { machine }\end{array}$ & $\begin{array}{c}\text { Tumble } \\
\text { dryer }\end{array}$ \\
\hline \multirow{2}{*}[\text{cycles/y}]{} & Real & 150 & 110 & 125 \\
\cline { 2 - 5 } & Simul. & 67 & 79 & 44 \\
\hline \multirow{2}{*}[\mathrm{kWh}/\mathrm{y}]{} & Real & 100 & 60 & 180 \\
\cline { 2 - 5 } & Simul. & 61 & 62 & 105 \\
\hline
\end{tabular}

\section{Model of wet appliances flexibility}

Two physical quantities are necessary to model the flexibility of the households subscribed to a ToU tariff:

- the probability of having a flexible configuration $p_{\text {flex }}$,

- the time of the configured shift $t_{\text {shift }}$.

A configuration state (flexible or not flexible) is predicted using a time-dependent Bernoulli process. After an occupant has started a wet appliance, a uniformly distributed random number $n$ in $[0,1$ [ is picked and is compared to the probability of flexible configuration $p_{\text {flex }}$. If the probability $p_{\text {flex }}$ is more than the random number $n$, a flexible configuration occurs. A shift $t_{\text {shift }}$ is then assigned to each flexible state.

\section{Modelling the probability of flexible configuration}

$p_{\text {flex }}$ is modelled using data collected during the LINEAR pilot experiment, which run from 2009 until 2014 in Belgium (D'hulst et al., 2015). As part of the LINEAR project, 418 smart wet appliances were deployed in 186 households during a period of 36 months. Users could decide if starting the appliance immediately (no window of flexibility) or if using the appliance in flexible mode by setting an ultimate finish time with a maximum of $24 \mathrm{~h}$ delay (flexibility window). Based on the available energy tariff, the smart appliance automatically optimized its start within this window.

Participants were rewarded using a capacity fee, which induced them to offer as much flexibility as possible. The capacity fee amounted to $1 €$ per 40 h of flexibility window configured and did not depend on the time of day. Furthermore, users were not aware of the varying demand response strategies implemented during the different phases of the pilot study. Hence, the resulting flexibility model can be potentially applied while studying any specific DR strategy and/or energy tariff structure.

Based on the results of the LINEAR study, the probability of flexible configuration $p_{\text {flex }}$ is found to depend on the time of the day (with a peak of flexibility in the evening), on the day of week (weekdays vs. weekend days) and on the type of wet appliance used. In particular, it is found that the dishwashers outperform the other wet appliances in terms of flexibility and have a mean probability of flexible configuration equal to $25 \%$. This was predictable since, for the case of the washing machines, users need to have an additional control over the finish time, so as not to leave the wet clothes too long inside the machine before drying them. This makes them less willing to provide flexibility, as compared to the dishwashers. However, unlike the LINEAR households, French households are manually shifting their washing machines and have control over the end time of the washing cycle. Because of this difference, it is here assumed that the probability of flexible configuration for the washing machines is the same as for the dishwashers and only depends on the time of the day and on the day of week, $p_{\text {flex }}(t)$ in Figure 6 .

This raises a very important point on how users engage with their appliances since they are not merely trying to 
optimize their behaviour based on a cost function as most modelling approaches assume (McKenna and Keane, 2016; Sancho-Tomás et al., 2017). They prioritize practical issues over costs. This also means that a smart washing machine that optimizes its cycle within a userpredefined time will not work in practise (as the LINEAR pilot experiment clearly demonstrates), with the exception of the case in which integrated washer dryers are used.

A different case is that of the tumble dryer, which needs to be started as soon as the washing machine is done. For this appliance, no flexibility is observed in the monitored data (ENERTECH, 2016). This is also evident from Figure 10 and Figure 11: the night share of the annual energy consumption for the households subscribed to a single-rate flat tariff is the same as for those subscribed to a two-rate ToU tariff.

\section{Modelling the time of the configured shift}

$t_{\text {shift }}$ is modelled based on the framework described in Figure 6, where the entire household is represented as an agent that make probabilistic decisions according to the specific ToU tariff he subscribed to. It is assumed that the ToU tariffs always include both a diurnal and a nocturnal period of off-peak hours, as it is most often the case in France. The off-peak hours of the day are set to start at either 13:00 or 14:00 and to end at either $16: 00$ or 17:00. While, the off-peak hours of the night are set to start at either 22:00, 23:00 or 00:00 and to end at either 05:00, 06:00 or 07:00. This reflects the main off-peak hours available in France (Enedis, 2019).

When a flexible configuration occurs, the occupant shifts its appliance to the next off-peak hours, either during the day or during the night. Energy data from 87 washing machines and 65 dishwashers monitored in 2008 for an average of 44 days in 100 French homes (ADEME et al., 2008) shows that users have a preference to shift their devices' loads during the off-peak hours of the night. It is therefore here assumed that $80 \%$ of the flexible cycles are shifted during the following night, $p_{\text {night }}=80 \%$.

Furthermore, each occupant decides if shifting its appliance either at beginning or at the end of the off-peak hours. Shifting at the end means to shift the appliance so that its cycle ends at the end of the off-peak hours. For the case of the day shift, the probability of shifting at the beginning is assumed to be equal to the probability of shifting at the end. While, for the case of the night shift, observed data (ADEME et al., 2008) shows that occupants tend to shift their dishwashers at the beginning of the off-peak periods, since there are not problems in letting the dishes inside the machine during the night. While, for the washing machines, occupants would rather not let the wet clothes inside the machine during the night and prefer to have their laundry finished early in the morning. Hence, the probability of day/night shift depends on the type of appliance used, $p_{b e g}(a) / p_{\text {end }}(a)$. It is here assumed that $80 \%$ of the flexible dishwasher cycles are shifted at the beginning of the night off-peak hours, $p_{b e g}(d w)=80 \%$, and $80 \%$ of the flexible washing machine cycles are shifted at the end of it, $p_{\text {end }}(w m)=80 \%$.

To account for the fact that occupants do not behave in a deterministic way, not all the appliances are shifted exactly at the beginning or exactly at the end. Randomization is introduced by anticipating (for the end case) and delaying (for the beginning case) the shift based on an exponential function with lambda equal to 1 .

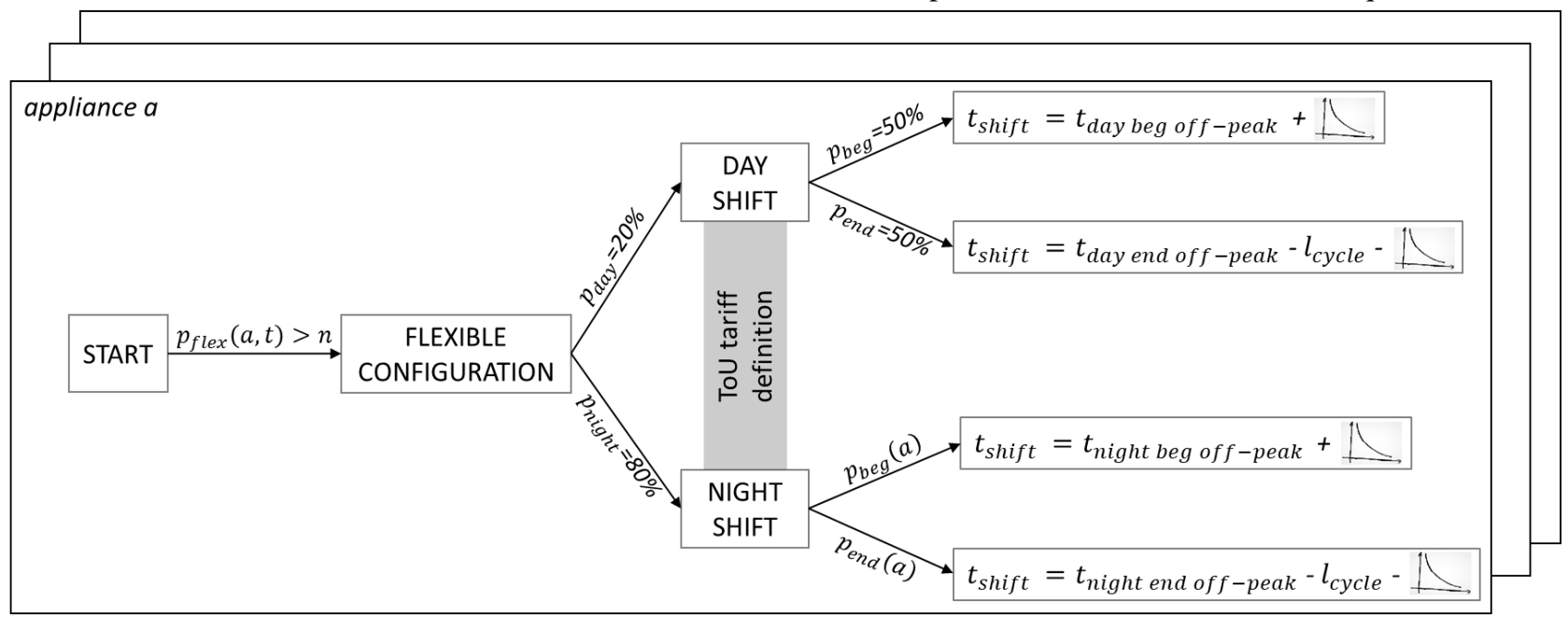

Figure 6: Simplified flowchart of the framework used to model occupants' configured shift $\left(t_{\text {shift }}\right)$.

\section{Results of the validation}

In Figure 7, Figure 8 and Figure 9 the distributions of the normalized hourly mean loads are shown both with and without the flexibility model. The flexibility model is only applied to the households that subscribed to a ToU tariff (41\%), which are randomly chosen among all the households. It can be noticed that the overlaying flexibility model improves the fitting between the simulated and the real data. This is particularly evident during the night, with a substantial increase of the load. This also means that simulating users' behaviour without accounting for their manual shifting at night results in a significant underestimation of the night load. 


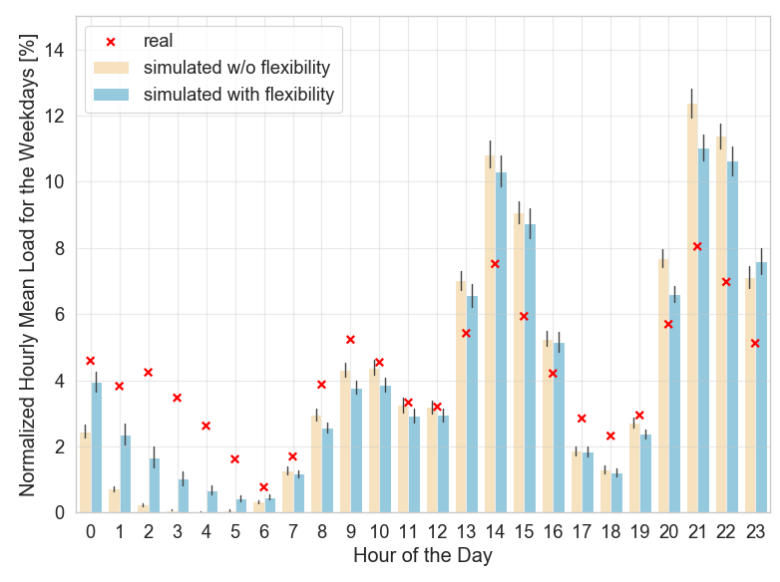

Figure 7: Normalized (with respect to the total daily load) hourly mean load for the dishwashers during the weekdays. The loads are given both with and without (w/o) the model of occupants' flexibility.

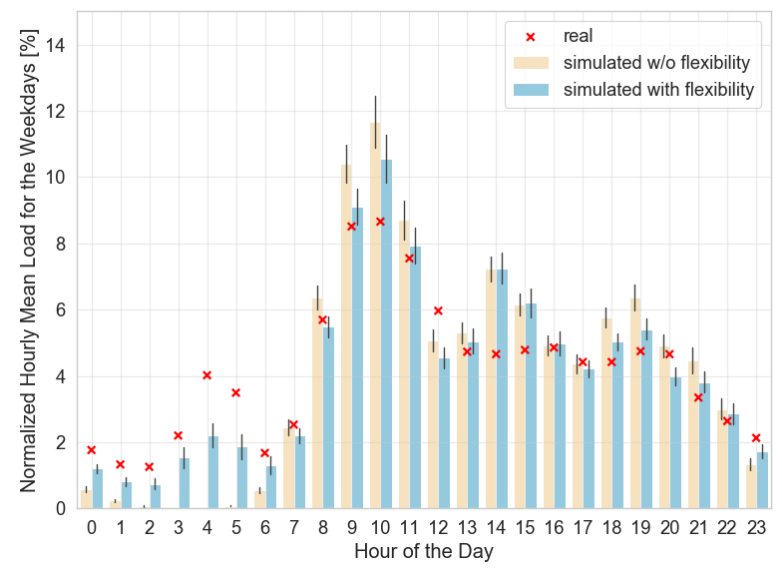

Figure 8: Normalized (with respect to the total daily load) hourly mean load for the washing machines during the weekdays. The loads are given both with and without the model of occupants' flexibility.

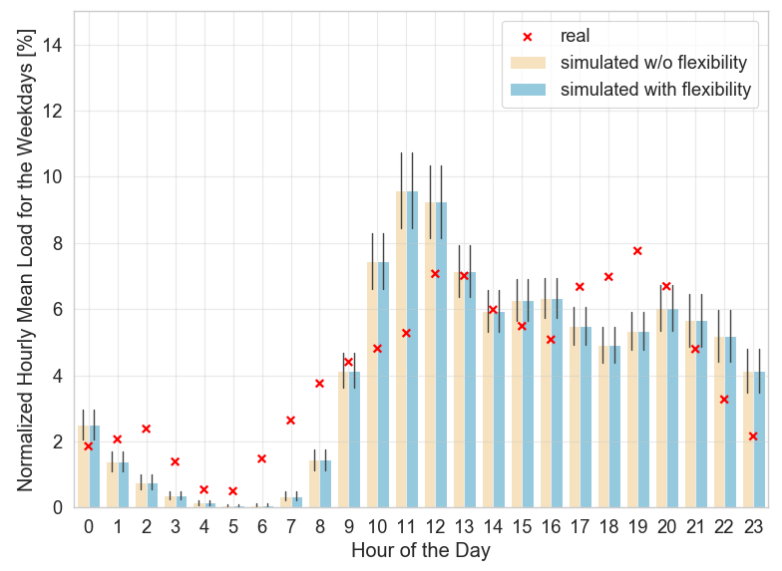

Figure 9: Normalized hourly mean load for the tumble driers during the weekdays. The loads are given both with and without (w/o) the model of occupants' flexibility.
There are still some problems with the occupants' stochastic model, which tends to underestimate some hourly peaks in consumption and overestimate others. In particular, the model underestimates the morning peak for the dishwashers, while overestimates it for the washing machines. The tumble dryer's model needs further development since it is not able to correctly reproduce the hourly distribution of the load.

Finally, Figure 10 and Figure 11 show the night share (from 22:30 to 06:30) of the annual energy consumption for households subscribed to a single-rate flat tariff and to a two-rate ToU tariff, respectively. The model is able to predict the night shares of consumption for the households subscribed to a two-rate ToU tariff.

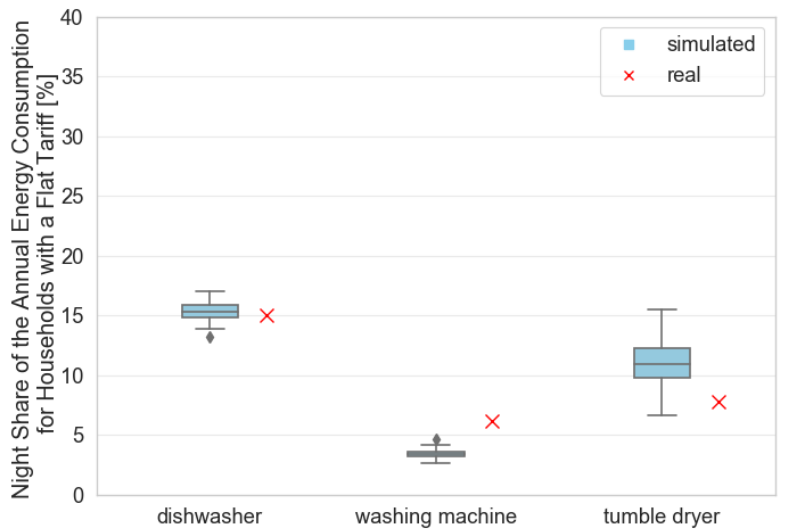

Figure 10: Night share (from 22:30 to 06:30) of the annual energy consumption for households subscribed to a single-rate flat tariff.

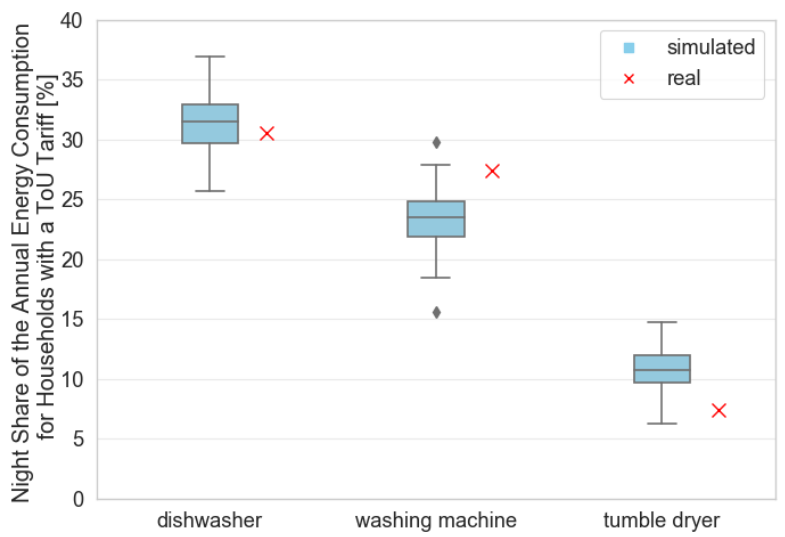

Figure 11: Night share (from 22:30 to 06:30) of the annual energy consumption for households subscribed to a two-rate ToU tariff.

\section{Discussion and Conclusion}

The results of the validation procedure show that the model is able to reproduce the annual number of cycles and the annual energy consumption at a mean level. However, it is not able to correctly simulate the diversity of the usage within the simulated population. A better modelling of the effect of the ToU tariff on the use of French wet appliances has been achieved and the model is able to predict the hourly load distribution and the night 
share of the total energy use of dishwashers and washing machines but not those of the tumble dryers.

In the future, further efforts should be dedicated to the development of the wet appliance usage model, especially for the tumble dryer. Also, the agent-based model used to predict the shifting of dishwashers and washing machines should be further developed using survey investigations to calibrate the probabilities $p_{\text {flex }}, p_{\text {day/night }}, p_{\text {beg/end }}$. A further development of the model could take into account the socio-demographic profile of each agent, which would determine the above probabilities, instead of using an average agent profile. The use of survey data would also make possible to extend the use of the flexibility model to other countries. Once the flexibility model is calibrated using survey data, it could be used:

- to quantify the flexibility potential of the wet appliances at national level by performing simulations on a reduced household sample representative of the national sample,

- to evaluate the effect of increasing penetration rates of the ToU tariff on the national flexibility potential,

- $\quad$ to study the impact of different types of ToU tariffs at different scale (district, city, region and national).

\section{Acknowledgement}

This research was funded by the French National Research Agency, CLEF project (ANR-17-CE22-000501).

\section{References}

ADEME, ENERTECH, \& EDF (2008). Campagne de Mesures Des Appareils de Production de Froid et Des Appareils de Lavage Dans 100 Logements.

AISE (2017). Pan-European Consumer Habits Survey 2017 - Perceptions of Cleanliness and Hygiene Cleaning Habits, Sustainability and Safety.

D'hulst, R., Labeeuw, W., Beusen, B., Claessens, S., Deconinck, G., \& Vanthournout, K. (2015). Demand Response Flexibility and Flexibility Potential of Residential Smart Appliances: Experiences from Large Pilot Test in Belgium. Applied Energy 155, 7990.

Dupret, M. \& Zimmermann, J.-P. (2017). Electricity Consumption of Cold Appliances, Washing Machines, Dishwashers, Tumble Dryers and Air Conditioners. On-Site Monitoring Campaign in 100 Households. Appliances, Products, Lighting and ICT 7, 1501-9.

Enedis (2019). Enedis Open Data. Retrieved 8 January 2019 (https://data.enedis.fr/explore/dataset/nbclients-inf-36/information/).

ENERTECH (2016). Campagne de Mesures Des Appareils de Production de Froid, Des Appareils de Lavage et de La Climatisation.

EU (2010). Commission Delegated Regulation (EU) No $1059 / 2010$ of 28 September 2010 Supplementing Directive 2010/30/EU of the European Parliament and of the Council with Regard to Energy Labelling of
Household Dishwashers. Official Journal of the European Union.

Fischer, D., Stephen, B., Flunk, A., Kreifels, N., Lindberg, K. B., Wille-Haussmann, B., \& Owens, E. H. (2017). Modeling the Effects of Variable Tariffs on Domestic Electric Load Profiles by Use of Occupant Behavior Submodels. IEEE Transactions on Smart Grid 8(6), 2685-93.

Gottwalt, S., Ketter, W., Block, C., Collins, J., \& Weinhardt, C. (2011). Demand Side Management-A Simulation of Household Behavior under Variable Prices. Energy Policy 39(12), 8163-74.

INSEE (2010a). Couples - Familles - Ménages En 2010.

INSEE (2010b). Statistics on Income and Living Conditions 2010.

INSEE (2010c). Time Use Survey 2009-2010.

McKenna, K. \& Keane, A. (2016). Residential Load Modeling of Price-Based Demand Response for Network Impact Studies. IEEE Transactions on Smart Grid 7(5), 2285-94.

Riederer, P., Partenay, V., Perez, N., Nocito, C., Trigance, R., \& Guiot, T. (2015). Development of a Simulation Platform for the Evaluation of District Energy System Performances. Proceedings from BS2015: 14th Conference of International Building Performance Simulation Association. Hyderabad (IN).

RTE (2017a). Bilan Prévisionnel de l'équilibre OffreDemande d'électricité En France.

RTE (2017b). Réseaux Électriques Intelligents : Valeur Économique, Environnementale et Déploiement d'ensemble.

Sancho-Tomás, A., Chapman, J., Sumner, M., \& Robinson, D. (2017). Extending No-MASS: MultiAgent Stochastic Simulation for Demand Response of Residential Appliances. Proceedings from BS2017: 15th Conference of International Building Performance Simulation Association. San Francisco (USA).

Stamminger, R. \& Schmitz, A. (2017). Load Profiles and Flexibility in Operation of Washing Machines and Dishwashers in Europe. International Journal of Consumer Studies 41, 178-187.

Venkatesan, N., Solanki, J., \& Solanki, S. K. (2012). Residential Demand Response Model and Impact on Voltage Profile and Losses of an Electric Distribution Network. Applied Energy 96, 84-91.

Yan, D., O’Brien, W., Hong, T., Feng, X., Burak Gunay, H., Tahmasebi, F., \& Mahdavi, A. (2015). Occupant Behavior Modeling for Building Performance Simulation: Current State and Future Challenges. Energy and Buildings 107, 264-78. 